\title{
Ethanol Augments Monosodium Urate-Induced NLRP3 Inflammasome Activation via Regulation of AhR and TXNIP in Human Macrophages
}

\author{
Seong-Kyu Kim ${ }^{1,2}$, Jung-Yoon Choe ${ }^{1,2}$, and Ki-Yeun Park ${ }^{2}$ \\ ${ }^{1}$ Division of Rheumatology, Department of Internal Medicine, Catholic University of Daegu School of Medicine, Daegu; \\ ${ }^{2}$ Arthritis and Autoimmunity Research Center, Catholic University of Daegu, Daegu, Korea.
}

Purpose: Ethanol elicits several inflammatory responses and affects the innate immune response. The aim of this study was to identify the mechanism by which ethanol affects uric acid-induced NLR family pyrin domain-containing 3 (NLRP3) inflammasome activation by regulation of aryl hydrocarbon receptor (AhR) and thioredoxin-interacting protein (TXNIP).

Materials and Methods: Human myeloid leukemia cells (U937 cells) were used to assess the role of ethanol in NLRP3 inflammasome activation induced by monosodium urate (MSU) crystals. Expression of target molecules, such as NLRP3 inflammasome components, AhR, and TXNIP, were measured using quantitative real-time PCR and Western blot analyses. The effect of ethanolinduced TXNIP on the NLRP3 inflammasome was assessed in human macrophages transfected with TXNIP siRNA.

Results: U937 cells treated with $100 \mathrm{mM}$ ethanol for $24 \mathrm{~h}$ induced NLRP3 and interleukin (IL)-1 $\beta$ expression. Ethanol increased reactive oxygen species generation in a time- and dose-dependent manner. AhR mRNA expression was downregulated in U937 cells treated with $100 \mathrm{mM}$ ethanol, whereas CYP1A1 mRNA expression increased. Treatment with ethanol increased NLRP3 and IL-1 $\beta$ mRNA and protein expression in U937 cells exposed to $1.0 \mathrm{mg} / \mathrm{mL}$ of MSU crystals for $24 \mathrm{~h}$. TXNIP expression in U937 cells incubated with both $100 \mathrm{mM}$ ethanol and $1.0 \mathrm{mg} / \mathrm{mL}$ of MSU crystals was significantly higher than in cells incubated with MSU crystals alone. Treatment with 100mM ethanol for $24 \mathrm{~h}$ downregulated NLRP3 and IL-1 $\beta$ expression in MSU crystal-activated U937 cells transfected with TXNIP siRNA, compared to those with scramble siRNA.

Conclusion: Ethanol stimulates uric acid-induced NLRP3 inflammasome activation through regression of AhR and upregulation of TXNIP.

Key Words: Ethanol, uric acid, NLRP3, inflammasome, AhR, TXNIP

\section{INTRODUCTION}

The NLR family pyrin domain-containing 3 (NLRP3) inflam-

\footnotetext{
Received: March 16, 2020 Revised: April 13, 2020

Accepted: April 14, 2020

Corresponding author: Seong-Kyu Kim, MD, PhD, Division of Rheumatology, Department of Internal Medicine, Arthritis and Autoimmunity Research Center, Catholic University of Daegu School of Medicine, 33 Duryugongwon-ro 17-gil, Nam-gu, Daegu 42472, Korea.

Tel: 82-53-650-3465, Fax: 82-53-629-8248, E-mail: kimsk714@cu.ac.kr

-The authors have no potential conflicts of interest to disclose.

(C) Copyright: Yonsei University College of Medicine 2020

This is an Open Access article distributed under the terms of the Creative Commons Attribution Non-Commercial License (https://creativecommons.org/licenses/ by-nc/4.0) which permits unrestricted non-commercial use, distribution, and reproduction in any medium, provided the original work is properly cited.
}

masome is activated by pathogen-associated molecular patterns (PAMPs) and endogenous danger-associated molecular patterns (DAMPs), including pore-forming toxins, bacteria, asbestos, alum, adenosine triphosphate (ATP), nigericin, and cholesterol crystals. ${ }^{1,2}$ Various mechanisms play a role in promoting NLRP3 inflammasome activation, including calcium flux, mitochondrial reactive oxygen species (ROS), and thioredoxin-interacting protein (TXNIP). ${ }^{3,4}$ Potent negative regulators have also been found to modulate NLRP3 inflammasome activation to maintain a balance between aberrant inflammation and beneficial effects for the host, such as tripartite-motif protein 30, nitric oxide, and aryl hydrocarbon receptor (AhR). ${ }^{5-7}$

Ethanol elicits various physiologic effects in abnormal cellular metabolism and tissue or organ damage. Some evidence on the conflicting effects of ethanol on NLRP3 inflammasome 
activation has been presented: Ethanol markedly attenuated activation of the NLRP3 inflammasome in response to diverse danger signals, including ATP and nigericin, in lipopolysaccharide (LPS)-primed macrophages ${ }^{8,9}$ In contrast, the NLRP3 inflammasome was shown to be responsible for the pathophysiology of alcohol-induced neuro-inflammation in experimental studies using brain tissue and neuronal cells..$^{10,11}$ TXNIP was found to be involved in activation of NLRP3 inflammasome after binding to NLRP3 in uric acid-mediated inflammation. ${ }^{12}$ Alcohol was also shown to induce hepatocyte pyroptosis through TXNIP overexpression and NLRP3 inflammasome, which is responsible for alcoholic hepatitis. ${ }^{13}$ However, there is a lack of studies on what role alcohol plays in regulating the function of TXNIP-induced NLRP3 inflammasome activation.

AhR is a ligand-mediated transcription factor that binds to multiple natural or synthetic ligands and thus is implicated in inflammation and the immune response. ${ }^{14,15}$ Recently, it was shown that ethanol could control the regulation of AhR activity and its target genes in mouse hepatic stellate cells. ${ }^{16}$ Furthermore, AhR has been found to inhibit activation of NLRP3 inflammasome. ${ }^{7}$ Monosodium urate (MSU) is also considered a danger signal for activation of the NLRP3 inflammasome in the pathogenesis of gout. ${ }^{3,17}$ The objective of this study was to analyze the mechanism by which ethanol regulates AhR and TXNIP expression on MSU-induced NLRP3 inflammasome activation in human macrophages.

\section{MATERIALS AND METHODS}

\section{Cell culture}

Human myeloid leukemia cells (U937 cells) were obtained from the Korean Cell Line Bank (KCLB, Seoul, South Korea) and maintained in RPMI 1640 medium (Gibco Laboratories, Grand Island, NY, USA) supplemented with $10 \%$ fetal bovine serum, $100 \mathrm{U} / \mathrm{mL}$ penicillin, and $100 \mu \mathrm{g} / \mathrm{mL}$ streptomycin. To induce differentiation, cells were treated with $100 \mathrm{nM}$ phorbol 12-myristate 13-acetate dissolved in dimethyl sulfoxide (DMSO) for $24 \mathrm{~h}$. MSU crystals were prepared by recrystallization from uric acid. PMA, uric acid, LPS, and DMSO were purchased from Sigma, and absolute ethanol (Merck, Darmstadt, Germany) was used in all experiments.

\section{Cell viability assay}

Cell viability was measured using a Cell Counting Kit-8 (CCK8) assay (Dojindo Laboratories, Kumamoto, Japan) according to the manufacturer's instructions. In brief, cells were seeded into 96-well plates at $5 \times 10^{3}$ cells per well and treated with ethanol $(0,10,50,100,200$, and $300 \mathrm{mM})$ for $24 \mathrm{~h}$, and each concentration was analyzed in triplicate. After treatment, $10 \mu \mathrm{L}$ of CCK-8 reagent was added, followed by incubation for $2 \mathrm{~h}$, and absorbance was measured with a microplate reader at $450 \mathrm{~nm}$.

\section{ROS measurement}

ROS were measured using a DCFDA cellular ROS detection assay kit (Abcam, Cambridge, UK) according to the manufacturer's instructions. Cells were seeded in 6 -well plates at $1 \times 10^{6}$ cells per well and treated with ethanol at the indicated doses for 1, 3, 6, 12, or $24 \mathrm{~h}$. After treatment, cells were harvested and transferred to 96 -well black microplates with $2.5 \times 10^{3}$ cells per well. The cells were then incubated with DCFDA solution for $45 \mathrm{~min}$ at $37^{\circ} \mathrm{C}$ in the dark. The supernatants were discarded and replaced with phosphate-buffered saline, and stained cells were measured using a fluorescence plate reader (BMG Lab Technologies, Offenburg, Germany) set to 485-nm excitation and 535-nm emission.

\section{Quantitative real time-polymerase chain reaction}

Cells $\left(2 \times 10^{6}\right)$ were stimulated with MSU $(0.1 \mathrm{mg} / \mathrm{mL})$ with or without ethanol treatment $(100 \mathrm{mM})$ for $24 \mathrm{~h}$. RNA was isolated from cultured cells using TRIzol reagent, and equal amounts of each sample were reverse transcribed into cDNA using a ReverTra Ace- $\alpha$-kit (Toyobo, Osaka, Japan) according to the manufacturer's instructions.

qRT-PCR was performed using the MiniOpticon ${ }^{\mathrm{TM}}$ RealTime PCR System (Bio-Rad Laboratories, Hercules, CA, USA) with SYBR Green PCR Master Mix (Toyobo, Osaka, Japan) at a final volume of $20 \mu \mathrm{L}$ consisting of $10 \mu \mathrm{L}$ SYBR $^{\circledR}$ Green Realtime PCR Master Mix (Toyobo), $10 \mathrm{pmol} / \mathrm{L}$ of each primer, $2 \mu \mathrm{L}$ of complementary DNA, and 6.4 $\mu \mathrm{L}$ of RNase-free water. GAP$\mathrm{DH}$ was used to normalize expression levels of target genes.

\section{Immunoblot analysis}

Total proteins were prepared using RIPA buffer $(50 \mathrm{mM}$ Tris$\mathrm{HCl}, \mathrm{pH} 8.0$, with $150 \mathrm{mM}$ sodium chloride, $1 \% \mathrm{NP}-40,0.5 \%$ sodium deoxycholate, and $0.1 \%$ sodium dodecyl sulfate) and supplemented with a protease inhibitor cocktail 1 tablet (Roche Applied Science, Mannheim, Germany). Protein concentrations were determined using Bradford Protein Assay Kits (BioRad Laboratories). Proteins $(50-60 \mu \mathrm{g})$ were electrophoresed on sodium dodecyl sulfate-polyacrylamide (SDS-PAGE) gels and then transferred to nitrocellulose membranes. After blocking with $5 \%$ bovine serum albumin, membranes were incubated with specific primary antibodies overnight at $4^{\circ} \mathrm{C}$, followed by incubation with secondary horseradish peroxidase-conjugated antibodies.

For extraction of secreted proteins, the supernatants were precipitated with a final $10 \%(\mathrm{w} / \mathrm{v})$ solution of trichloroacetic acid (Merck, Darmstadt, Germany) on ice for $10 \mathrm{~min}$ and subsequent centrifugation at $13000 \mathrm{rpm}$ at $4^{\circ} \mathrm{C}$ for $30 \mathrm{~min}$. The supernatant was discarded, and the pellet was washed with cold acetone $100 \%$, followed by addition of Laemmli buffer and incubation in a heat block at $95^{\circ} \mathrm{C}$ for $10 \mathrm{~min}$. Equal amounts of protein were then analyzed by $10 \%$ SDS-PAGE.

Reactive proteins were visualized using an enhanced SuperSignal ${ }^{\circledR}$ West Pico chemiluminescent kit (Thermo Scientific, 
Rockford, IL, USA) for $1 \mathrm{~min}$, exposed with the ChemiDoc TM XRS system, and analyzed using Quantity One W software (BioRad Laboratories).

\section{Transfection of siRNA}

Silencer Select siRNA (Human TXNIP: 116391) was transfected into cells using Lipofectamine RNAiMAX reagent (Invitrogen, Carlsbad, CA, USA) according to the manufacturer's instructions. Briefly, the day before transfection, cells were seeded at $1 \times 10^{5}$ cells per well in 24 -well plates. When cells reached $60^{-}$ $70 \%$ confluence, they were transfected with $100 \mathrm{nM}$ of siRNA using lipofectamine RNAiMAX in Opti-MEM media. Expression of transfected cells was identified by qRT-PCR and Western blot assay after cells were incubated for $72 \mathrm{~h}$.

\section{Statistical analysis}

Values are described as means \pm standard deviations. Differences between two groups were assessed using the Mann-Whitney U-test with PRISM software (version 5.0, GraphPad Software Inc., La Jolla, CA, USA). $p<0.05$ was considered statistically significant.

\section{RESULTS}

\section{Ethanol enhances NLRP3 and IL-1 $\beta$ gene and protein expression}

The CCK-8 assay revealed changes in cell viability of U937 cells with increasing ethanol concentration in human macrophages (Fig. 1A). There was a significant decline in cell viability with 200 and $300 \mathrm{mM}$ ethanol, which was less than $80 \%$ of the cell viability found in the control group ( $0 \mathrm{mM}$ ethanol). Subsequent experiments were performed at a concentration of $100 \mathrm{mM}$ ethanol. Chronic stimulation with ethanol $(100 \mathrm{mM}$ for $24 \mathrm{~h}$ ) induced significant mRNA expression of NLRP3 and IL-1 $\beta$ genes in U937 cells ( $p<0.05$ of both) (Fig. 1B). In the assessment of the effect of ethanol on NLRP3 and interleukin (IL)$1 \beta$ protein production with time, we found more enhanced expression of NLRP3 and IL-1 $\beta$ proteins after 6,12 , or $24 \mathrm{~h}$ of ethanol stimulation than those in untreated macrophages (Fig. 1C). Consistent with the observed protein expression in Fig. 1C, U937 cells treated with $100 \mathrm{mM}$ ethanol showed NLRP3 and IL-1 $\beta$ mRNA expression at 6,12 , and $24 \mathrm{~h}$ in time-dependent manner (Fig. 1D).

\section{Ethanol induces ROS generation and suppresses AhR in human macrophages}

ROS generation increased significantly in human macrophages treated with $100 \mathrm{mM}$ ethanol for 6,12 , and $24 \mathrm{~h}$, compared to U937 macrophages treated without ethanol (Fig. 2A). In addition, chronic stimulation with 10 and $50 \mathrm{mM}$ ethanol for $24 \mathrm{~h}$ also increased ROS generation. Fig. 2B depicts time-dependent changes in AhR and CYP1A1 mRNA expression after stim- ulation with $100 \mathrm{mM}$ ethanol in U937 cells. AhR mRNA expression was markedly decreased in macrophages treated with 100 $\mathrm{mM}$ ethanol for $1,3,6,12$, and $24 \mathrm{~h}$, compared to untreated macrophages. In contrast, CYPAlAl mRNA expression significantly increased in U937 cells treated with $100 \mathrm{mM}$ ethanol for 12 and $24 \mathrm{~h}$, compared to untreated macrophages.

\section{Ethanol augments NLRP3 inflammasome activation under stimulation with LPS and MSU crystals} Cell viability in the presence of varying MSU crystal concentrations $(0,0.05,0.1,0.2,0.3 \mathrm{mg} / \mathrm{mL})$ was assessed in human U937 macrophages under stimulation with LPS and ethanol (Fig. 3A). There was a significant decrease in cell viability with 0.2 and $0.3 \mathrm{mg} / \mathrm{mL}$ of MSU crystals, compared to macrophages without MSU crystals. We next evaluated whether ethanol augmented NLRP3 inflammasome activation under stimulation with LPS and MSU (Fig. 3B). NLRP3 and IL-1 $\beta$ mRNA expression in U937 cells incubated with LPS $(1 \mu \mathrm{g})$ and MSU crystals $(0.1 \mathrm{mg})$ was much more enhanced after the addition of ethanol ( $p<0.05$ of both), but not caspase- 1 and ASC mRNA expression ( $p>0.05$ of both). Macrophages cotreated with ethanol for $24 \mathrm{~h}$ displayed higher expression of NLRP3, caspase-1, and IL-1 $\beta$ under stimulation with LPS and MSU crystals compared to macrophages treated only with LPS and MSU crystals (Fig. 3C), but not ASC protein (data not shown).

\section{TXNIP is involved in ethanol-induced NLRP3 inflammasome activation in macrophages primed with LPS and MSU crystals}

TXNIP mRNA expression was markedly increased in U937 cells treated with $100 \mathrm{mM}$ ethanol for $24 \mathrm{~h}$, compared to untreated macrophages $(p<0.05)$ (Fig. 4A). Ethanol $(100 \mathrm{mM}$ for $24 \mathrm{~h}$ ) induced a significant increase in TXNIP mRNA expression in U937 cells treated with LPS and MSU crystals, compared to U937 macrophages without ethanol $(p<0.05)$ (Fig. 4B). Ethanol promoted TXNIP protein production in human macrophages, compared to those treated without ethanol under condition of LPS and MSU crystals (Fig. 4C).

Under stimulation with LPS, MSU crystals, and ethanol, NLRP3 and IL-1 $\beta$ mRNA expression was much lower in macrophages transfected with TXNIP siRNA than those transfected with siRNA scramble ( $p<0.05$ of both) (Fig. 4D). Meanwhile, caspase- 1 and ASC mRNA expression did not differ between U937 cells transfected with and without siRNA TXNIP (Fig. $4 \mathrm{D})$. Consistently, NLRP3 3 and IL-1 $\beta$ protein expression in macrophages transfected with siRNA TXNIP was markedly decreased, compared to macrophages without siRNA TXNIP ( $p<$ 0.001 and $p<0.05$, respectively) (Fig. $4 \mathrm{E}$ ).

\section{DISCUSSION}

Ethanol has been recognized to play a crucial regulatory role 

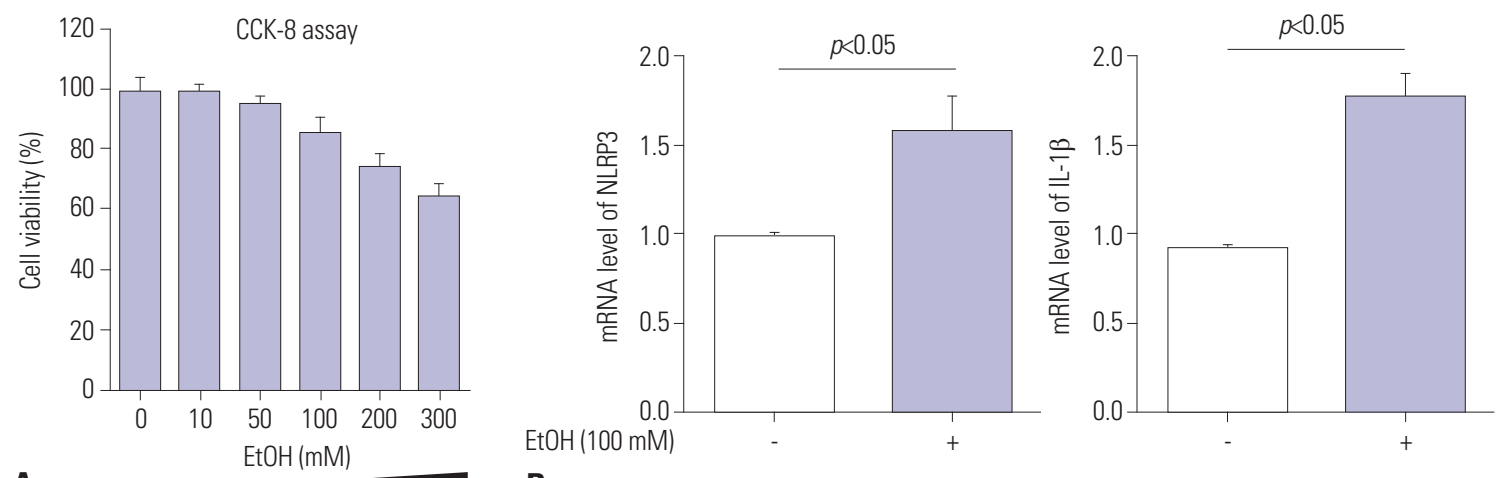

A

B
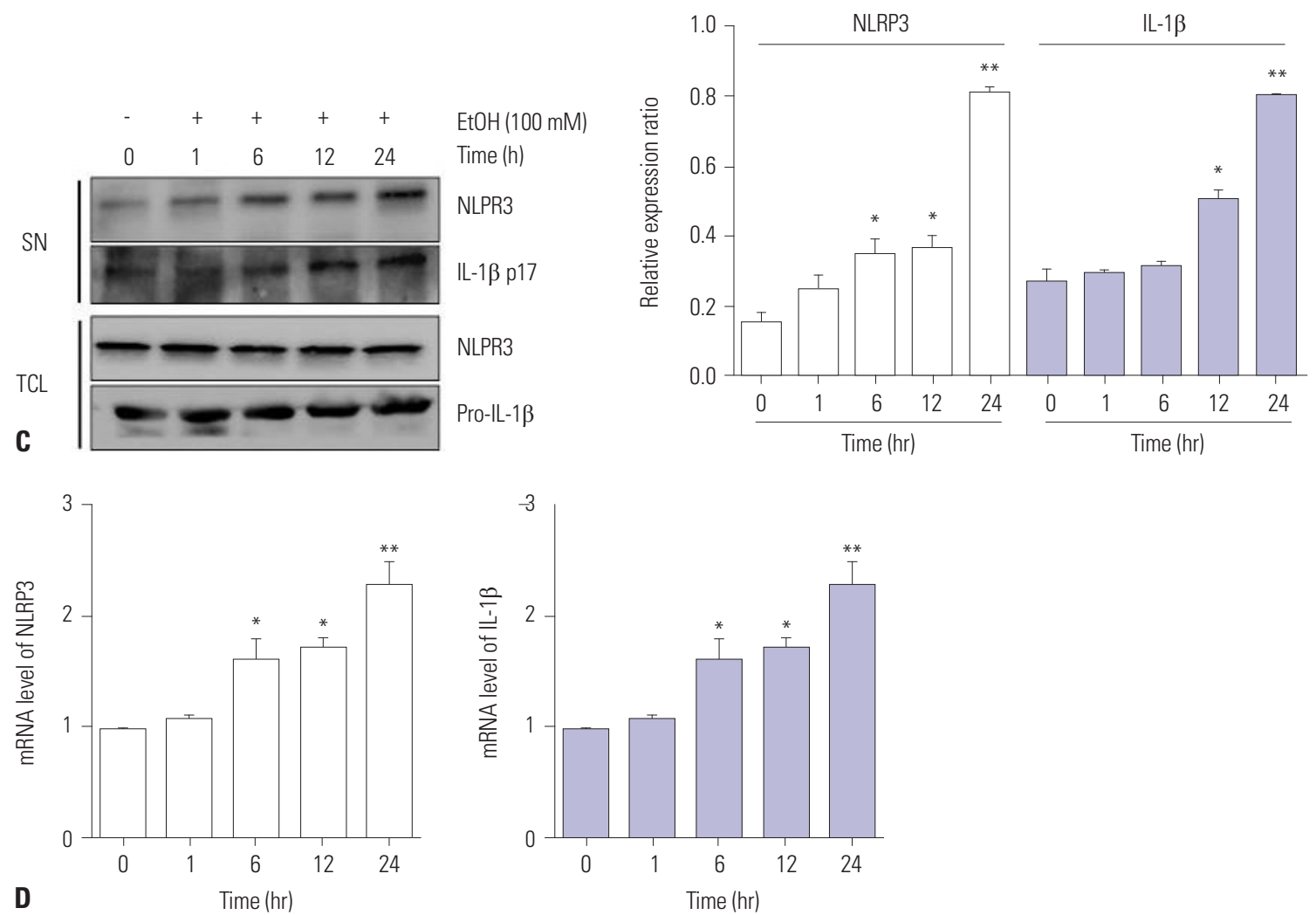

Fig. 1. Ethanol induces NLRP3 and IL-1 $\beta$ expression. (A) Cell viability of U937 cells treated with $0,10,50,100,200$, and 300 mM ethanol. (B) mRNA expression of NLRP3 and IL-1 $\beta$ in U937 cells incubated with and without $100 \mathrm{mM}$ ethanol for $24 \mathrm{~h}$. (C) NLRP3 and IL-1 $\beta$ protein expression in U937 cells treated with $100 \mathrm{mM}$ ethanol for $0,1,6,12$, and $24 \mathrm{~h} .{ }^{*} p<0.01$ and ${ }^{* *} p<0.001$ compared to untreated cells. (D) NLRP3 and IL-1 $\beta$ mRNA expression in U937 cells treated with $100 \mathrm{mM}$ ethanol for 0, 1, 6, 12, and $24 \mathrm{~h} .{ }^{*} p<0.05$ and ${ }^{* *} p<0.01$ compared to untreated cells. CCK-8, Cell Counting Kit-8; NLRP3, NLR family pyrin domain-containing 3; IL, interleukin; SN: supernatants, TCL: total cell lysate.

in immune and inflammatory responses in alcoholic liver disease, inflammation in the central nerve system, gout, and others. ${ }^{10,13,18}$ Recent studies have proposed that ethanol might be responsible for regulation of the innate immune system, particularly in NLRP3 inflammasome activation. ${ }^{8-11}$ Alcohol consumption has been shown to be associated with hyperuricemia and an increased risk of the development of gout. ${ }^{18}$ However, the mechanism by which alcohol affects the inflammatory response observed in gout, especially through NLRP3 inflammasome activation, has remained unknown. In this study, we found that chronic ethanol exposure promotes uric acid-induced NLRP3 inflammasome activation through regression of AhR expression and increased TXNIP expression in human macrophages.

AhR is a ligand-dependent transcription factor important in cell differentiation, cell death, inflammation, and the immune response in multiple types of inflammatory cells, including macrophages and dendritic cells. ${ }^{14,15}$ In binding to its ligands, such as benzopyrene, flavonoids, and dioxins, AhR interacts with the xenobiotic-response element located in the promoter of target genes within the nucleus, resulting in upregulation of their transcription, including CYP1A1. Alcohol consumption induces generation of a variety of chemical ligands that could bind to AhR, including tryptophan catabolites and arachidon- 

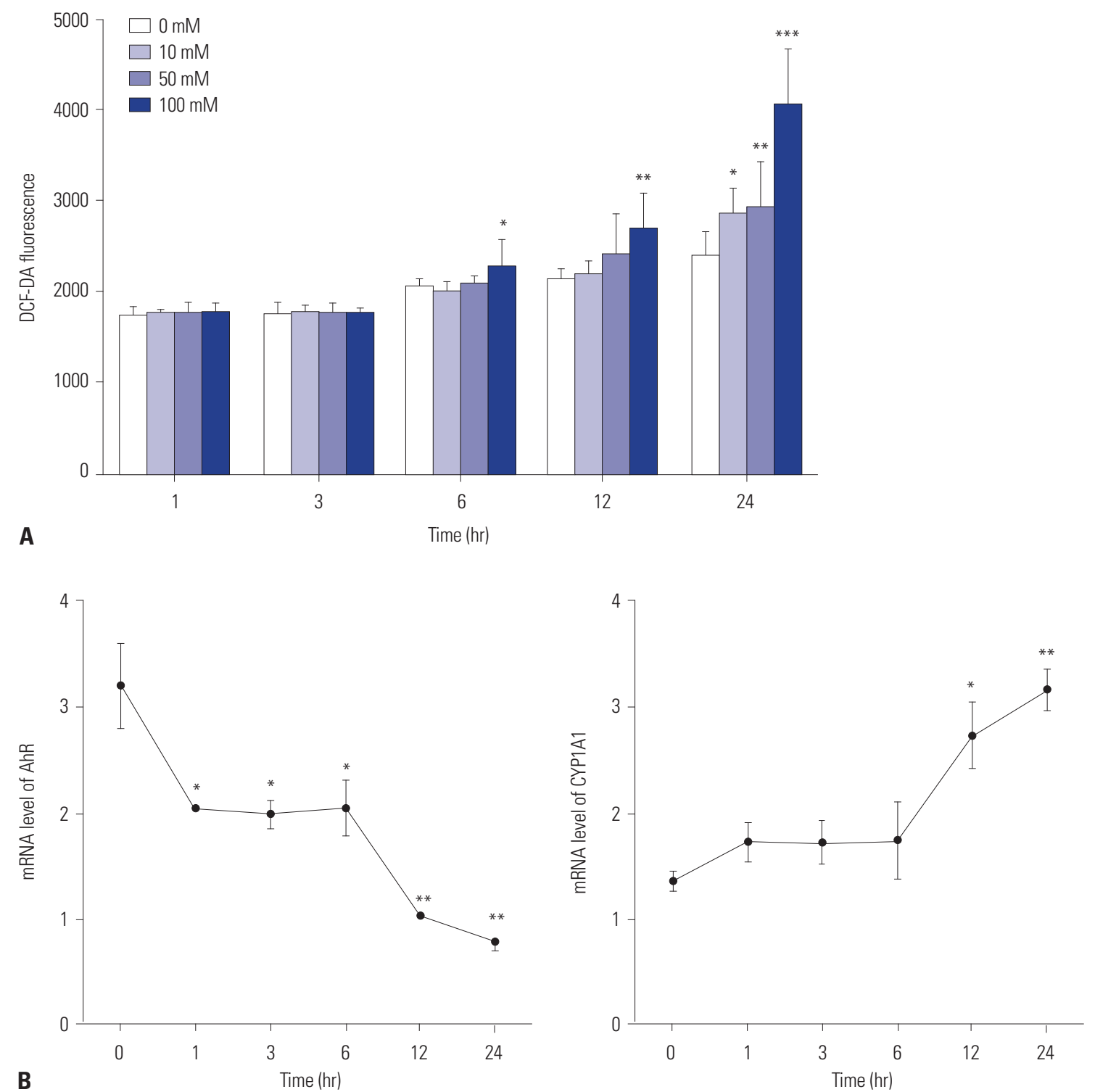

Fig. 2. Ethanol regulates ROS generation and AhR expression in U937 cells. (A) ROS measurement of U937 cells treated with ethanol using DCF-DA cellular ROS detection assay. ${ }^{*} p<0.05,{ }^{* *} p<0.01$, and ${ }^{* * *} p<0.001$ compared to cells treated without ethanol. (B) mRNA expression of AhR and CYP1A1 in U937 cells treated with $100 \mathrm{mM}$ ethanol for $0,1,3,6,12$, and $24 \mathrm{~h} .{ }^{*} p<0.01$ and ${ }^{* *} p<0.001$ compared to cells treated without ethanol. DCF-DA, Dichlorofluorescin diacetate; AhR, aryl hydrocarbon receptor; ROS, reactive oxygen species.

ic acid metabolites..$^{19,20}$ Recently, Zhang, et al. ${ }^{16}$ demonstrated that ethanol exposure to mouse hepatic stellate cells activated AhR, upregulated target genes CYPIA1 and CYP1B1, and increased CYP1Al promoter activity, although the AhR response may not be specific to ethanol. Another study showed that AhR was involved in IL-23-dependent restoration of IL-22 after ethanol exposure and burn injury. In contrast, intestinal lymphoid Peyer's patches cells cultured with an AhR inhibitor produced significantly less IL-22, suggesting that functional activity of AhR could be regulated by ethanol. Consistent with these results, we confirmed the inhibitory effect of ethanol exposure on AhR in human macrophages in a time-dependent manner. Ethanol-induced chemical ligands involved with AhR in macrophages need to be identified in future studies, because we did not assess potential candidate molecules.

Dysregulation of NLRP3 inflammasomes activated by diverse PAMPs and DAMPs results in production and release of pro-inflammatory cytokines, such as IL-1 $\beta$ and IL-18, which leads to enhanced inflammatory responses, ${ }^{1,2}$ although the mechanism underlying the activation of inflammation remains unclear. TXNIP has been linked to binding to NLRP3 after dissociation of TXNIP from thioredoxin (TRX) in response to oxidative stress, such as ROS generation, resulting in enhanced NLRP3 inflammasome activation..$^{12}$ Disturbance of TRX/ TXNIP signaling is considered a critical pathogenic factor in several inflammatory diseases, including diabetes mellitus, obesity, lung disease, and gout. ${ }^{4}$ It was recently reported that exposure to $100 \mathrm{mM}$ ethanol for $48 \mathrm{~h}$ induces overexpression 
A

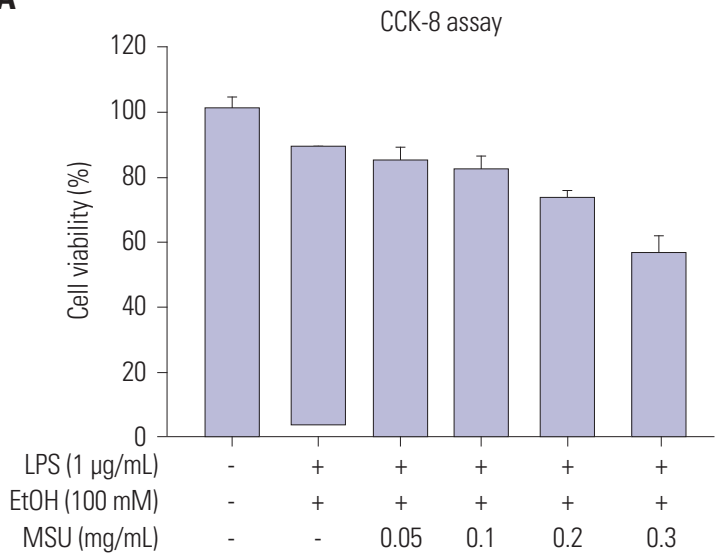

C
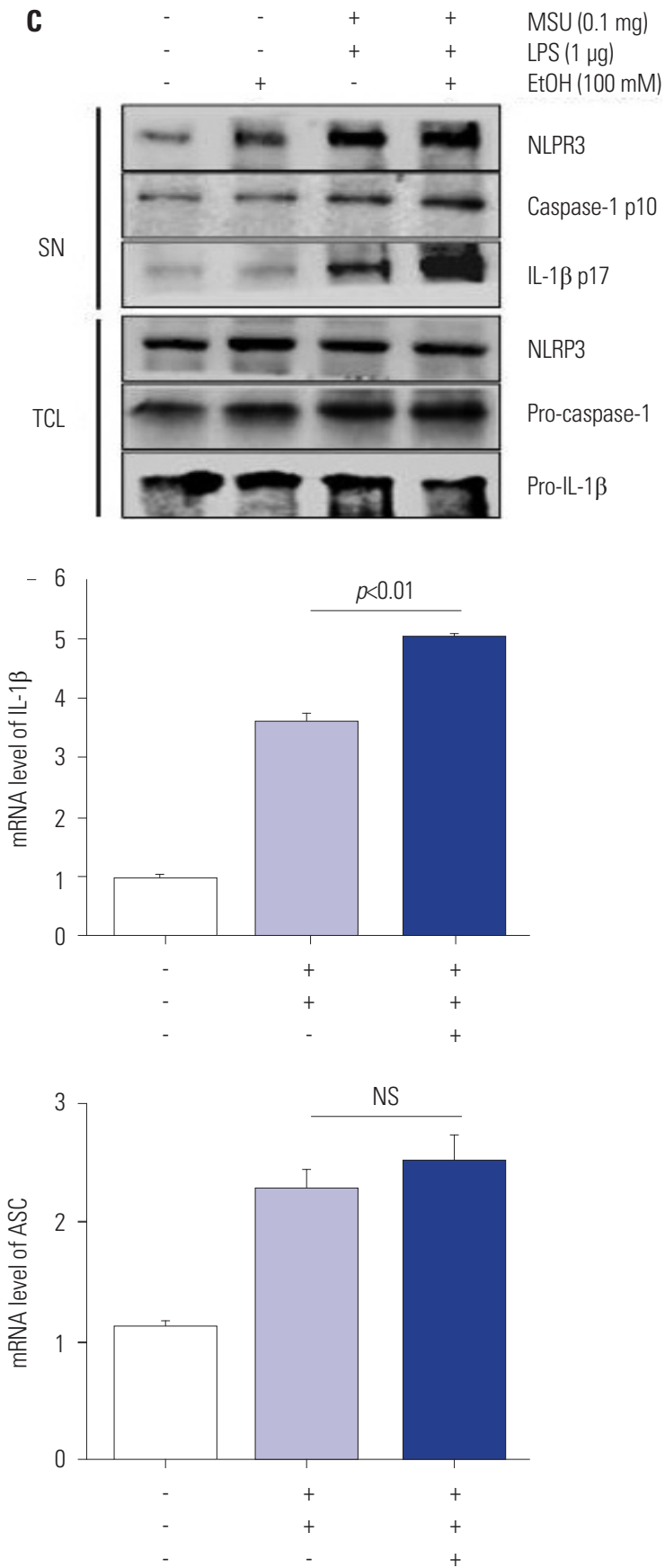

Fig. 3. Ethanol promotes NLRP3 inflammasome in U937 cells stimulated by LPS and MSU crystals. (A) Cell viability of U937 cells primed with LPS and ethanol after treatment with $0,0.05,0.1,0.2$, and $0.3 \mathrm{mg} / \mathrm{mL}$ MSU crystals. (B) mRNA expression of NLRP3 inflammasome components and IL-1 $1 \beta$ in U937 cells primed with MSU and LPS with and without ethanol. (C) NLRP3 inflammasome components and IL-1 $\beta$ protein expression in U937 cells primed with MSU and LPS with and without ethanol. CCK-8, Cell Counting Kit-8; LPS, lipopolysaccharide; MSU, monosodium urate; NLRP3, NLR family pyrin domain-containing 3; IL, interleukin; ASC, apoptosis-associated speck-like protein containing a caspase-recruitment domain.

of TXNIP mRNA and protein, which is involved in activation of the NLRP3 inflammasome in experimental mouse hepatocytes and AML-12 cells, leading to hepatocyte pyroptosis through activation of caspase- $1 .{ }^{13}$ In our study, we found that U937 cells treated with $100 \mathrm{mM}$ ethanol for $24 \mathrm{~h}$ also showed increased TXNIP protein expression. In addition, ethanol induced greater expression of TXNIP mRNA and protein in macrophages treated with MSU crystals. Furthermore, TXNIP-deficient macro- phages transfected with TXNIP siRNA showed a significant decrease of NLRP3 and IL-1 $\beta$ mRNA and protein expression. Although the previous study did not provide a specific mechanism of upregulation of TXNIP in hepatocytes incubated with ethanol, ${ }^{13}$ we observed that ethanol increased ROS generation in a time- and dose-dependent manner. Based on this finding, we suggest that ROS-mediated TXNIP might play a crucial role in ethanol-induced NLRP3 inflammasome activation. 
A

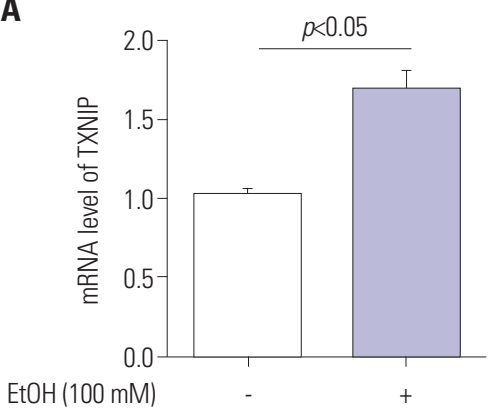

B

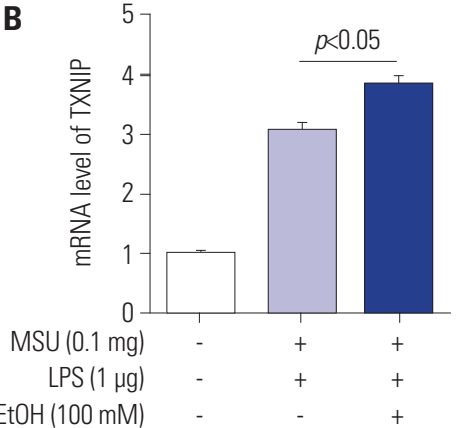

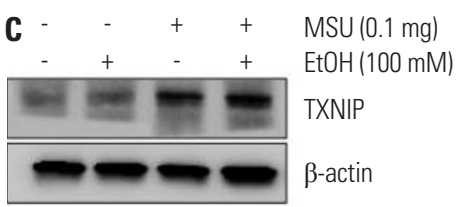

D

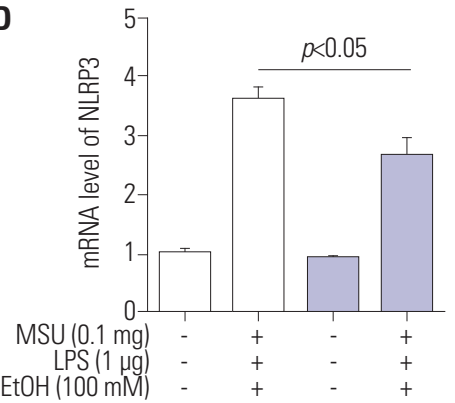

NS

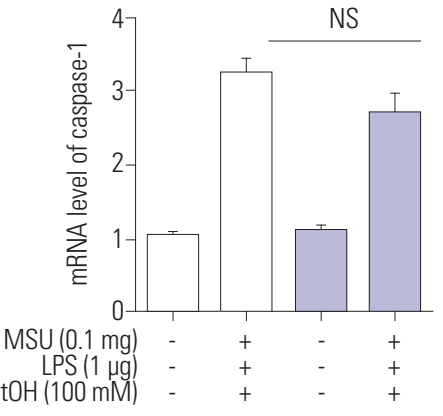

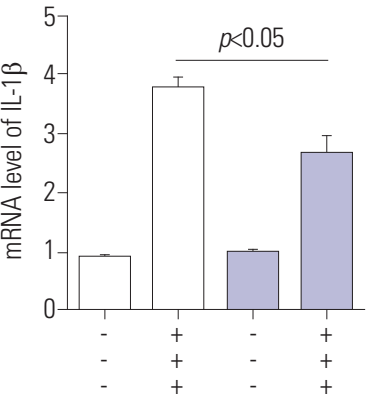

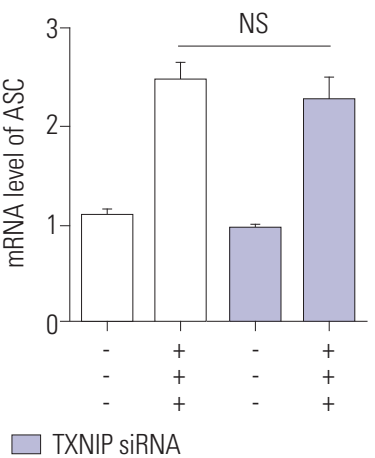

$\mathbf{E}$
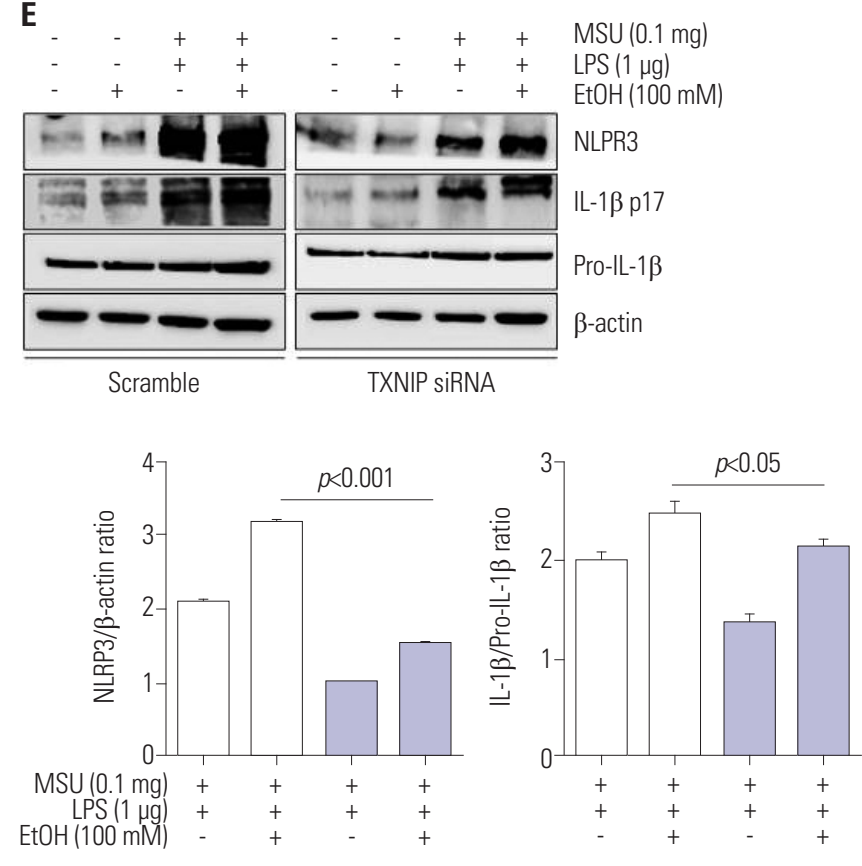

Fig. 4. Ethanol-mediated TXNIP involves NLRP3 inflammasome activation. (A) mRNA expression of TXNIP in U937 cells treated with and without 100 $\mathrm{mM}$ ethanol for $24 \mathrm{~h}$. (B) mRNA expression of TXNIP in U937 cells primed with MSU and LPS with and without $100 \mathrm{mM}$ ethanol for $24 \mathrm{~h}$. (C) TXNIP protein expression in U937 cells primed with MSU and LPS with and without $100 \mathrm{mM}$ ethanol for $24 \mathrm{~h}$. (D) mRNA expression of NLRP3 inflammasome components and IL-1 $\beta$ in U937 cells transfected with and without TXNIP siRNA. (E) NLRP3 and IL-1 $\beta$ protein expression in U937 cells transfected with and without TXNIP siRNA. TXNIP, thioredoxin-interacting protein; NLRP3, NLR family pyrin domain-containing 3; LPS, lipopolysaccharide; MSU, monosodium urate; IL, interleukin; ASC, apoptosis-associated speck-like protein containing a caspase-recruitment domain.

As a priming step for NLRP3 inflammasome activation, activation of the transcription factor nuclear factor- $\mathrm{kB}$ pathway through toll-like receptors leads to secretion of immature inflammatory cytokines pro-IL-1 $\beta$ and pro-IL-18. ${ }^{1,2}$ In addition, upregulation of some inflammasome components like NLPR3 is transcriptionally induced in response to LPS or other cytokines, which ultimately leads to enhanced NLRP3 protein expression in the cytosol for NLRP3 inflammasome activation. ${ }^{21,22}$ In a previous study, AhR was found to negatively regulate NLRP3 inflammasome activation in mouse peritoneal macrophages through suppressing NLRP3 level at the transcriptional level by replacing the AhR-ligand-ARNT complex at the two sides of the $\kappa B$ site in the NLRP3 promoter. ${ }^{7}$ Consistently, we also noted that U937 cells exposed to $100 \mathrm{mM}$ ethanol for $24 \mathrm{~h}$ exhibited induced enhanced mRNA expression of NLRP3 and
IL-1 $\beta$. AhR might be considered an endogenous inhibitor to NLRP3 expression. The clinical significance of ethanol-induced down-regulation of AhR has not been noted. However, NLRP3 expression, which is at low levels, could be relatively limited at the priming step in uric acid-NLRP3 inflammasome activation. Based on down-regulation of AhR by ethanol exposure, ${ }^{16}$ ethanol plays a role in enhanced release of pro-inflammatory cytokines, including IL-1 $\beta$, in the uric acid-NLRP3 inflammasome activation interaction.

Ethanol has both pro-inflammatory and anti-inflammatory effects through promoting or inhibiting NLRP3 inflammasome activation. Some studies using human or mouse macrophages have described inhibitory effects of ethanol on the NLRP3 inflammasome. ${ }^{8,9}$ In contrast, acute ethanol exposure (10 mM) has been shown to induce the highest IL-1 $\beta$ expression through 


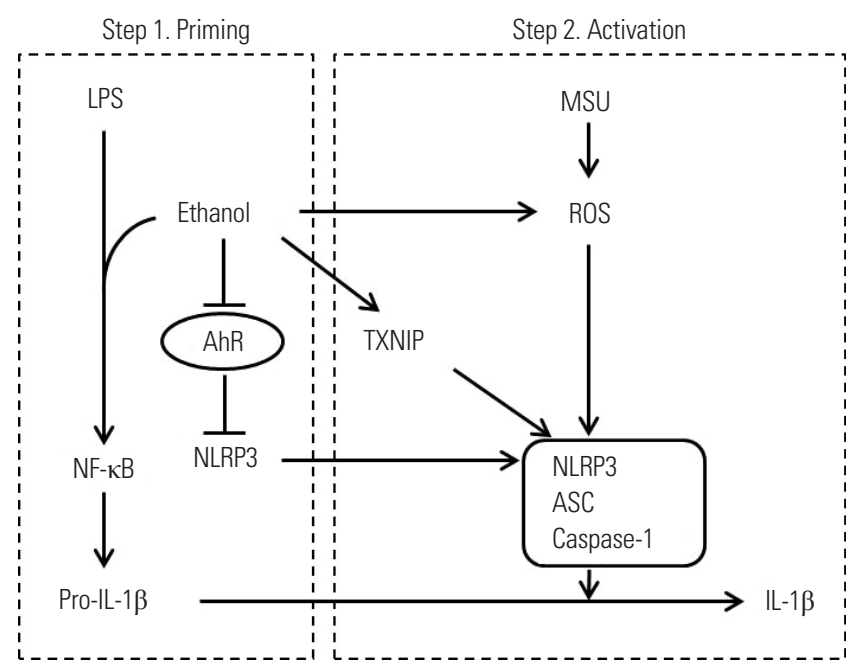

Fig. 5. A scheme illustrating the mechanism by which ethanol regulates AhR, TXNIP, NLRP3, and IL-1 $\beta$ expression in human macrophage U937 cells. Ethanol stimulates NLRP3 transcription through down-regulation of AhR in U937 cells treated with LPS. TXNIP expression is induced by ethanol stimulation. Ultimately, ethanol enhances activation of NLRP3 inflammasome and induces activation of IL-1B. LPS, lipopolysaccharide; MSU, monosodium urate; ROS, reactive oxygen species; AhR, aryl hydrocarbon receptor; TXNIP, thioredoxin-interacting protein; NLRP3, NLR family pyrin domain-containing 3 ; NF- $\mathrm{KB}$, nuclear factor- $\mathrm{\kappa} B$; IL, interleukin; ASC, apoptosis-associated speck-like protein containing a caspase-recruitment domain.

upregulation of the P2X7 purinergic receptor in monocytederived macrophages. ${ }^{23}$ In addition, we found that ethanol exposure for 7 and $48 \mathrm{~h}$ did not induce or inhibit components of the NLRP3 inflammasome, such as NLRP3, ASC, and caspase-1. Meanwhile, however, we also observed that NLRP3 inflammasome activation was induced through suppression of AhR and enhanced expression of TXNIP with chronic alcohol exposure, but not acute or low dose exposure. Some evidence can be provided to explain these conflicting results: a high concentration of ethanol allows near-surface fluidity and deformability, resulting in an increasing possibility of interaction with cytoplasmic molecules, including protein tyrosine phosphatase and lysosomes. ${ }^{8,9,24}$ In contrast, a low dose of ethanol can affect cell surface receptors, like the P2X7 receptor. ${ }^{23}$ Therefore, ethanol appears to have elicited different responses to inflammation depending on the tissue or cell type.

In conclusion, we identified that chronic ethanol exposure to human macrophages induces NLRP3 inflammasome activation stimulated by both LPS and MSU crystals, as shown at Fig. 5. AhR, a cytosolic ligand-activated transcription factor, was suppressed by ethanol treatment, resulting in blockage of NLRP3 expression at the transcriptional level. In addition, ethanol treatment in MSU crystal-induced macrophages augmented upregulation of TXNIP expression, with an effect on regulation of NLRP3 inflammasome activation. Therefore, we suggest that chronic ethanol exposure plays a crucial role in promoting uric acid-induced NLRP3 inflammasome activation, a potential link in the interaction between ethanol consumption and uric acid-related diseases, such as gout.

\section{ACKNOWLEDGEMENTS}

This work was supported by a research grant from YUHAN.

\section{AUTHOR CONTRIBUTIONS}

Conceptualization: all authors. Data curation: all authors. Formal analysis: Seong-Kyu Kim and Jung-Yoon Choe. Funding acquisition: Seong-Kyu Kim. Investigation: Seong-Kyu Kim and Ki-Yeun Park. Methodology: all authors. Project administration: Seong-Kyu Kim. Resources: all authors. Software: Seong-Kyu Kim and Ki-Yeun Park. Supervision: Seong-Kyu Kim. Validation: all authors. Visualization: Seong-Kyu Kim and Ki-Yeun Park. Writing_original draft: Seong-Kyu Kim and Ki-Yeun Park. Writing—review \& editing: Seong-Kyu Kim. Approval of final manuscript: all authors.

\section{ORCID iDs}

Seong-Kyu Kim Jung-Yoon Choe Ki-Yeun Park http://orcid.org/0000-0002-7780-0167

http://orcid.org/0000-0003-0957-0395

http://orcid.org/0000-0002-0837-3595

\section{REFERENCES}

1. Martinon F, Mayor A, Tschopp J. The inflammasomes: guardians of the body. Annu Rev Immunol 2009;27:229-65.

2. Schroder K, Tschopp J. The inflammasomes. Cell 2010;140:82132.

3. Zhou R, Yazdi AS, Menu P, Tschopp J. A role for mitochondria in NLRP3 inflammasome activation. Nature 2011;469:221-5.

4. Yoshihara E, Masaki S, Matsuo Y, Chen Z, Tian H, Yodoi J. Thioredoxin/Txnip: redoxisome, as a redox switch for the pathogenesis of diseases. Front Immunol 2014;4:514.

5. Hu Y, Mao K, Zeng Y, Chen S, Tao Z, Yang C, et al. Tripartite-motif protein 30 negatively regulates NLRP3 inflammasome activation by modulating reactive oxygen species production. J Immunol 2010;185:7699-705.

6. Mao K, Chen S, Chen M, Ma Y, Wang Y, Huang B, et al. Nitric oxide suppresses NLRP3 inflammasome activation and protects against LPS-induced septic shock. Cell Res 2013;23:201-12.

7. Huai W, Zhao R, Song H, Zhao J, Zhang L, Zhang L, et al. Aryl hydrocarbon receptor negatively regulates NLRP3 inflammasome activity by inhibiting NLRP3 transcription. Nat Commun 2014;5:4738.

8. Hoyt LR, Ather JL, Randall MJ, DePuccio DP, Landry CC, Wewers MD, et al. Ethanol and other short-chain alcohols inhibit NLRP3 inflammasome activation through protein tyrosine phosphatase stimulation. J Immunol 2016;197:1322-34.

9. Nurmi K, Virkanen J, Rajamäki K, Niemi K, Kovanen PT, Eklund KK. Ethanol inhibits activation of NLRP3 and AIM2 inflammasomes in human macrophages--a novel anti-inflammatory action of alcohol. PLoS One 2013;8:e78537.

10. Lippai D, Bala S, Petrasek J, Csak T, Levin I, Kurt-Jones EA, et al. Alcohol-induced IL-1 $\beta$ in the brain is mediated by NLRP3/ASC inflammasome activation that amplifies neuroinflammation. J Leukoc Biol 2013;94:171-82.

11. De Filippis L, Halikere A, McGowan H, Moore JC, Tischfield JA, Hart RP, et al. Ethanol-mediated activation of the NLRP3 inflammasome in iPS cells and iPS cells-derived neural progenitor cells. 
Mol Brain 2016;9:51.

12. Zhou R, Tardivel A, Thorens B, Choi I, Tschopp J. Thioredoxin-interacting protein links oxidative stress to inflammasome activation. Nat Immunol 2010;11:136-40.

13. Heo MJ, Kim TH, You JS, Blaya D, Sancho-Bru P, Kim SG. Alcohol dysregulates miR-148a in hepatocytes through FoxO1, facilitating pyroptosis via TXNIP overexpression. Gut 2019;68:708-20.

14. Quintana FJ. The aryl hydrocarbon receptor: a molecular pathway for the environmental control of the immune response. Immunology 2013;138:183-9.

15. Quintana FJ, Sherr DH. Aryl hydrocarbon receptor control of adaptive immunity. Pharmacol Rev 2013;65:1148-61.

16. Zhang HF, Lin XH, Yang H, Zhou LC, Guo YL, Barnett JV, et al. Regulation of the activity and expression of aryl hydrocarbon receptor by ethanol in mouse hepatic stellate cells. Alcohol Clin Exp Res 2012;36:1873-81.

17. Martinon F, Pétrilli V, Mayor A, Tardivel A, Tschopp J. Gout-associated uric acid crystals activate the NALP3 inflammasome. Nature 2006;440:237-41.

18. Choi HK, Atkinson K, Karlson EW, Willett W, Curhan G. Alcohol intake and risk of incident gout in men: a prospective study. Lan- cet 2004;363:1277-81.

19. Joshi AD, Carter DE, Harper TA Jr, Elferink CJ. Aryl hydrocarbon receptor-dependent stanniocalcin 2 induction by cinnabarinic acid provides cytoprotection against endoplasmic reticulum and oxidative stress. J Pharmacol Exp Ther 2015;353:201-12.

20. Luo J, Lindström CL, Donahue A, Miller MW. Differential effects of ethanol on the expression of cyclo-oxygenase in cultured cortical astrocytes and neurons. J Neurochem 2001;76:1354-63.

21. Guarda G, Zenger M, Yazdi AS, Schroder K, Ferrero I, Menu P, et al. Differential expression of NLRP3 among hematopoietic cells. J Immunol 2011;186:2529-34.

22. Hornung V, Latz E. Critical functions of priming and lysosomal damage for NLRP3 activation. Eur J Immunol 2010;40:620-3.

23. Le Daré B, Victoni T, Bodin A, Vlach M, Vene E, Loyer P, et al. Ethanol upregulates the P2X7 purinergic receptor in human macrophages. Fundam Clin Pharmacol 2019;33:63-74.

24. Sonmez M, Ince HY, Yalcin O, Ajdžanović V, Spasojević I, Meiselman HJ, et al. The effect of alcohols on red blood cell mechanical properties and membrane fluidity depends on their molecular size. PLoS One 2013;8:e76579. 